\title{
Correction: Feasibility of identifying and describing the burden of early-onset metabolic syndrome in primary care electronic medical record data: a cross-sectional analysis
}

Errors occurred in an article published Nov. 24, 2020. ${ }^{1}$

In Figure 3, the number of participants within the metabolic syndrome group for the overweight and obese category should have been $645 / 700$, corresponding to a corrected percentage of $92.1 \%$. The percentage given in the second paragraph of the Results section, first sentence, should also have been $92.1 \%$.

In Figure 4, the missing body mass index total should have been $43 / 700$, corresponding to a corrected percentage of $6.1 \%$. The percentage given in the first paragraph of the Missing data subsection in the Results should also have been $6.1 \%$.

These errors have been corrected at cmajopen.ca.

\section{Reference}

1. Boisvenue JJ, Oliva CU, Manca DP, et al. Feasibility of identifying and describing the burden of early-onset metabolic syndrome in primary care electronic medical record data: a cross-sectional analysis. CMAF Open 2020;8: E779-E87.

CMAJ Open 2021. DOI:10.9778/cmajo.20210099 